ken, dat voor de groep accountants, die ik hierbij steeds op het oog heb, de functie van accountant onverenigbaar is met die van ambtenaar; zij zijn in eerste instantie accountant, moeten als zodanig hun onafhankelijkheid bewaren en kunnen in wezen geen ambtenaar zijn. Op welke wijze er voor de moeilijkheden, die hier rijzen, een oplossing zou kunnen worden gevonden, wil ik in het midden laten. Alleen nog dit, ik geloof, dat hier een vakbelang ligt voor alle accountants, want de overheidsaccountant-ambtenaar is niet, zoals bijvoorbeeld de interne accountant, opgesloten in één bedrijf; hij verricht zijn arbeid evengoed in het openbaar verkeer, zij het ook in een andere vorm daarvan, als de accountant in het vrije beroep. Het is een bezwaar wanneer hier ambtenaar en accountant in het vrije beroep naast elkaar werkzaam zijn, op de duur zou dat m.i. wel eens tot een aantasting van de functie in het algemeen, dus ook in het vrije beroep, kunnen leiden.

\title{
STATEMENTS ON AUDITING PROCEDURE
}

bewerkt door Drs. D. E. Beutick

Sinds October 1939 heeft het Committee on Auditing Procedure van het American Institute of Accountants een serie "Statements on Auditing Procedure" uitgegeven, waarvan er tot nu toe 22 zijn verschenen.

Richard C. Lytle, die verbonden is aan de staf van het Institute, heeft een samenvattend overzicht samengesteld van deze statements, van welk overzicht hieronder een bewerking volgt.

Gedurende de laatste 30 jaar heeft het American Institute of Accountants vele belangrijke bijdragen geleverd tot de ontwikkeling van de accountancy, een ontwikkeling welke noodzakelijk was teneinde gelijke tred te kunnen houden met de steeds ingewikkelder wordende verhoudingen in het bedrijfsleven en de snel veranderende omstandigheden.

Een vroege bijdrage was een memorandum, dat, verschenen in het Federal Reserve Bulletin (April 1917) en herdrukt in 1918, in brede kring werd verspreid. Het memorandum gaf zekere minimum eisen aan, die gesteld moesten worden bij de controle van "financial statements" 1)

In 1929 werd het memorandum, nadat het door het Institute was herzien, teneinde het aan te passen aan de sedert de opstelling plaats gehad hebbende ontwikkeling van de accountancy, gepubliceerd door de Federal Reserve Board onder de titel "Verification of Financial Statements".

De jongste revisie vond plaats in 19,36 en werd door het Institute gepubliceerd als ,Examinations of Financial Statements by Independent Pu blic Accountants".

Sinds 1936 zijn echter verschillende onderdelen hiervan weer verouderd; zij werden gewijzigd in de serie "Statements on Auditing Procedure", uitgegeven door het Committee on Auditing Procedure van het Institute.

Deze ..Statements" hebben betrekking op de functie en de verantwoordelijkheid van de accountant, zijn verklaring of rapport, de omvang van de controle en de controle in de loop van het jaar.

1) In het hiernavolgende in de regel vertaald met .,(jaar) rekening".

$\mathrm{ma} \mathrm{b}$ blz. 202 


\section{Functie en verantwoordelijkheid van de accountant}

De functie van de (independent certified) public accountant is het onderzoek van de administratie van de onderneming, in bepaalde gevallen het verkrijgen van bevestiging van buiten het bedrijf, het verkrijgen en beoordelen van aanvullende toelichtingen en inlichtingen van de directie en het personeel, in die mate als de accountant noodzakelijk acht om hem in staat te stellen te beoordelen of de overgelegde rekening een getrouw beeld geeft van de positie van de onderneming en de resultaten over een bepaalde periode behaald.

Over het algemeen is zijn functie beperkt tot het verslag uitbrengen over toestanden, ontstaan als gevolg van transacties, die in het verleden hebben plaats gevonden. ${ }^{2}$ )

De verantwoordelijkheid van de accountant is af te leiden uit uitspraken van het committee op verschillende plaatsen. Zo werd gesteld, dat, hoewel aan zekere minimum eisen moet worden voldaan wat betreft de te verrichten werkzaamheden, teneinde tot een oordeel te komen, de uiteindelijke verantwoordelijkheid hiervoor bij de accountant berust; hij zal moeten beslissen, welke werkwijze volgens zijn vakkundig oordeel geeigend is.

De accountant mag slechts een oordeel uitspreken na een onderzoek, dat een behoorlijke basis oplevert om tot zulk een oordeel te komen.

De verklaring van de accountant moet duidelijk en ondubbelzinnig zijn. $\mathrm{Hij}$ moet niet het oordeel uitspreken, dat de stukken een getrouw beeld geven van de positie van het bedrijf en de resultaten, in overeenstemming met algemeen aanvaarde principes van boekhouden, als hij zodanige voorbehouden maakt, dat zijn verklaring daardoor wordt teniet gedaan, of indien het onderzoek minder van omvang is geweest dan hij noodzakelijk acht. In dergelijke omstandigheden moet de accountant zich in zijn rapport beperken tot het weergeven van zijn bevindingen, en, indien ter zake dienende, van zijn redenen voor het achterwege laten van een oordeel. ${ }^{3}$ )

Hoewel het opsporen van verduisteringen niet het primaire doel is van het normale onderzoek door een public accountant, is het zijn plicht het systeem van interne controle (internal check and accounting control) na te gaan, teneinde te kunnen beoordelen in welke, mate hij het verantwoord acht daarop te vertrouwen.

De verantwoordelijkheid van de accountant strekt zich niet uit tot het opmaken van de rekening. De directie is direct verantwoordelijk voor de instandhouding van een behoorlijk boekhoudsysteem, voor de juiste aantekening van de transacties in de boeken, en voor instandhouding van de activa. Op de leiding rust ook primair de verantwoordelijkheid tegenover de aandeelhouders en de crediteuren voor de juistheid en de volledigheid van de stukken, betrekking hebbende op de positie en de resultaten.

\section{Verklaring of rapport van de accountant.}

Het committee nam op verschillende tijdstippen enkele gevallen in beschouwing, waarbij het mededelen van een oordeel, gefundeerd op een beperkt onderzoek, werd besproken.

In Statements No. 2 werd het geval behandeld, waarbij de normaal vereiste voornaamste bewijsstukken voor het grootste deel niet ter beschikking van de accountant stonden. Met betrekking tot de vlottende

2) Statements on Auditing Procedure No. 1 blz. 3.

3) Statements on Auditing Procedure No. 1 blz, 4 en 5 .

m a b blz. 203 
activa en een belangrijk deel van de transacties van de client zou hij voornamelijk hebben moeten steunen op het feit, dat het bedrijf goed en conservatief werd geleid en dat de afzonderlijke posten waren gecontroleerd door de interne controle-afdeling van het bedrijf.

De normale controle was ten aanzien van belangrijke vlottende activa vrijwel geheel achterwege gebleven.

Het committee was van mening, dat er onder deze ornstandigheden geen voldoende grond was om zelfs een verklaring met een voorbehoud te rechtvaardigen.

De functie van de interne accountant vergelijkend met die van de public accountant, was het committee van oordeel, dat de interne controle-afdelingen een belangrijk onderdeel vormen van het systeem van interne controle (check and control) voora! indien een onderneming vele fabrieken of kantoren telt.

Het werk van de interne accountant beperkt de omvang van het controle- en checkwerk (testing and checking) van de zelfstandige accountant.

De doeleinden van beider onderzoek en de punten, waarop daarbij de nadruk wordt gelegd, lopen evenwel geenszins parallel. De interne controle legt in het bijzonder de nadruk op de accuratesse van de boekhouding, op het feit, dat deze in overeenstemming is met de in het bedrijf toegepaste boekhoudsystemen, en het opsporen van onregelmatigheden en mogelijke tekorten.

De public accountant let eveneens op deze punten, maar zij zijn voor hem niet het belangrijkste. Hij houdt zich meer in het bijzonder bezig met de juistheid van oordeel van de leiding, zoals deze tot uitdrukking komt in de rekening en de overeenstemming daarvan met goed koopmansgebruik. 4)

Verder is een van de waarborgen, welke de onafhankelijke controle geeft deze, dat zij wordt uitgevoerd door ienand, die niet afhankelijk is van de gecontroleerde onderneming.

Op grond hiervan kan een interne controle, hoe efficient ook, niet beschouwd worden als een vervanging van het werk van de public accountant. 5)

In Statements No. 11 werd een ander geval behandeld, waarin een bijzonder en belangrijk deel van de controle, met betrekking tot een over heersend deel van de activa (bevestiging van hypotheekleningen en rekeningen van a'andeelhouders bij een federale spaar - en leenbank) achterwege was gelaten.

De vraag werd besproken, of een dergelijke lacune voldoende reden was, om het uitspreken van een oordeel te beletten. Daartoe was het noodzakelijk te overwegen, welke mogelijkheden tot misvattingen van betekenis als gevolg van deze lacune konden ontstaan. Aangezien er voldoende alternatieve middelen waren om deze posten vast te stellen, en werd aangenomen, dat deze middelen waren toegepast, was het committee van mening, dat het risico van een misvatting niet voldoende groot geacht kon worden, om het geven van een verklaring met een voorbehoud te beletten. Het committee legde er evenwel de nadruk op, dat het de public accountant is, die zich een oordeel moet vormen; hij is de enige, die beoordelen

4) Generally accepted accounting principles and conventions.

5) Statements on Auditing Procedure No. 2, blz. 15. 
kan, of hij een verklaring kan geven en hij moet bereid zijn de verantwoordelijkheid op zich te nemen, indien hij een beperkte verklaring afgeeft. ${ }^{6}$ )

Het derde geval heeft betrekking op het onderzoek bij een ,face-amount certificate company". Daarbij rees de vraag, of een public accountant gerechtigd zou zijn een verklaring met voorbehoud af te geven, indien zijn onderzoek zich niet had uitgestrekt tot de reserves voor de verplichtingen tegenover houders van certificaten van zulk een vennootschap.

Het committee was van mening, dat, aangezien deze reserves een overgroot deel vertegenwoordigen van de verplichtingen van zulk een vennootschap en van zeer grote betekenis zijn bij het vaststellen van het inkomen over een periode, een onderzoek, dat zich niet uitstrekte tot de beoordeling van het bedrag van de reserves en de juistheid van de principes toegepast bij de vaststelling van deze reserves, een onvoldoende basis vormt voor een oordeel over de betrouwbaarheid van de rekening. Het committee was van oordeel, dat een onderzoek op deze basis een zodanig voorbehoud noodzakelijk zou maken, met betrekking tot de omvang van de uitgevoerde werkzaamheden, dat de verklaring daardoor te niet zou worden gedaan, zodat de accountant in dit geval zelfs niet gerechtigd werd geacht een verklaring met voorbehoud te geven.

Het committee verklaarde, dat naar zijn mening de ,.standards of auditing procedure", van toepassing op regelmatige heel of halfjaarlijkse rekeningen, eveneens van toepassing zijn op tussentijdse rekeningen als een oordeel wordt gegeven.

\section{Extensions of auditing procedure.}

\section{Voorraden.}

Het committee gaf in statements No. 1 te kennen, dat, it should be generally accepted auditing procedure" dat, indien de accountant een verklaring afgeeft met betrekking tot een onderneming, waarin de voorraden een belangrijke plaats innemen, hij in aansluiting aan de controle van de voorraadadministratie, waar dit mogelijk en rationeel is, in persoon aanwezig moet zijn bij het opnemen der voorraden, dan wel zich daarbij moet laten vertegenwoordigen. Hij moet zich door waarneming en informaties op de hoogte stellen van de juistheid van de inventarisatiemethoden en van de mate van het vertrouwen, dat gesteld mag worden in de voorraadopgaven van de client en de voorraadadministratie. In dit verband kan de accountant eisen, dat monsters uit de voorraden in zijn bijzijn worden getrokken en gekeurd.

Vindt de inventarisatie slechts plaats aan het einde van de boekingsperiode, dan zal het gewoonlijk noodzakelijk zijn het voorgaande op dat ogenblik in toepassing te brengen.

In die gevallen, waarin door het bedrijf een behoorlijk bijgehouden en gecontroleerde boekhouding wordt gevoerd volgens het systeem der „permanence de l'inventaire", gesteund door een volledige inventarisatie op een niet met de balansdatum samenvallende datum, dan wel individuele posten van tijd tot tijd worden opgenomen, zodat de hoeveelheid van ieder artikel tenminste eenmaal per jaar wordt vergeleken met de voorraadadministratie, zal het voldoende zijn de bovenomschreven werkzaamheden uit te voeren op een willekeurige door de accountant gekozen datum. Zijn doel is daarbij zich te overtuigen van de betrouwbaarheid van de voor -

6) Statements on Auditing Procedure No. 10, blz. 81. 
raadadministratie en na te gaan, of er zodanig op kan worden vertrouwd, dat zij als grondslag kan dienen voor de voorraadcijfers op de balans.

In die gevallen, waar de voorraden in vemen zijn opgeslagen, of bij andere instellingen in bewaring zijn gegeven, kan met een schriftelijke bevestiging van degene, die de activa in bewaring heeft genomen, worden volstaan. Betreft het evenwel een belangrijk deel van de vlottende activa of de totale activa, dan zal de accountant een aanvullend onderzoek moeten instellen.

Het is duidelijk, dat, indien de accountant dergelijke controlewerkzaamheden verricht met betrekking tot voorraden, hij dit doet met het doel zich te overtuigen van de geloofwaardigheid van de door de directie verstrekte gegevens met betrekking tot hoeveelheid en toestand der voor raden en dat hij zich niet voordoet als taxateur of deskundige. ${ }^{7}$ )

Het committee wees op het fundamentele verschil tussen de inventarisatie door de cliënt en de waarneming van de inventarisatie of het testen van ide voorraden door de public accountant. Het is een essentiële verantwoordelijkheid van de cliënt, om het bedrag der voorraden vast te stellen, dat in de financiële overzichten zal worden opgenomen. De functie van de public accountant is zichzelf te overtuigen van de geloofwaardigheid van de door de cliënt overgelegde gegevens. Deze functie dient evenwel in geen opzicht gezien te worden als een vervanging van de inventarisatie door de cliënt. ${ }^{8}$ )

De vraag werd gesteld, of het practisch uitvoerbaar en rationeel is om de voorraadopneming bij te wonen van warenhuizen, filiaalbedrijven, afbetalingszaken en andere detaillisten. Deze vraag werd besproken in Statements No. 3 en het committee was van oordeel, dat een dergelijke werkwijze inderdaad practisch uitvoerbaar en rationeel is.

Het committee wijst er in Statements No. 16 op, dat de voorraadopneming niet het enige gegeven is, waarop de accountant zijn oordeel baseert. De voorraadopneming en de administratie vormen elkaars complement en bevestigen elkaar.

De term ..generally accepted auditing standards applicable in the circumstances" betekent niet, dat in dat geval de methode van controle werd toegepast, welke in de meerderheid van alle gevallen zou worden toegepast, doch zij omvat veeleer de matregelen, die de accountants in het algemeen voldoende zouden achten in dergelijke omstandigheden. ${ }^{9}$ )

Het herziene voorschrift van de ,Securities and Exchange Commission" met betrekking tot accountantsverklaringen bevatte een bepaling. dat , indien bepaalde controlewerkzaamheden over het algemeen als normaal beschouwd met betrekking tot belangrijke posten achterwege zijn gebleven, een speciale omschrijving van zulke werkzaamheden en van de redenen, waarom zij achterwege werden gelaten, wordt verlangd." Het committee wees er op, dat een dergelijke mededeling gedaan moest wor den in alle gevallen, waarin de voorraadopneming niet was bijgewoond, doch ook in die gevallen, waarin dit noch practisch uitvoerbaar, noch rationeel was en zelfs, indien de accountant zich op andere wijze had overtuigd.10)

\section{Debiteuren.}

Statements No. 1 propageert het opnemen van de van de debiteur te

7) Statements on Auditing Procedure No. 1, blz. 6.

8) Statements on Auditing Procedure No. 17, blz. 120.

$\left.{ }^{9}\right)$ Statements on Auditing Procedure No. 6, blz. 46.

10) Statements on Auditing Procedure No. 12, blz. 89. 
verkrijgen bevestiging van uitstaande posten in de controlewerkzaamheden. Het committee wilde dit beschouwen als ,.general accepted auditing procedure" in die gevallen, waarin dit practisch uitvoerbaar en rationeel is en waar het totaal van wissels en uitstaande rekeningen een belangrijk deel uitmaakt van de vlottende activa van een onderneming.

De wijze, warap de bevestiging van de debiteur zal worden verkregen, wordt aan het oordeel van de accountant overgelaten. Twee methoden worden daarbij algemeen toegepast, de "positieve" en de "negatieve" methode.

Bij de positieve methode wordt de debiteur verzocht aan de accountant de juistheid van het opgegeven bedrag van het saldo te bevestigen. De negatieve methode vraagt slechts een antwoord, indien thet saldo onjuist is. De negatieve methode moet niet gebruikt worden als de accountant reden heeft om aan te nemen, dat aan het verzoek geen aandacht zal worden geschonken, of dat hij geen antwoord zou krijgen, indien het bedrag, aan' de debiteur opgegeven, af zou wijken van diens eigen gegevens.

Indien de te ontvangen bedragen verschuldigd zijn door een betrekkelijk gering aantal bedrijven en de bedragen relatief hoog zijn, zullen deze omstandigheden de tendens hebben de interne controle minder effectief te maken. Het wordt dan wenselijk geacht de positieve methode toe te passen.

Indien het een zeer groot aantal rekeningen betreft, te incasseren van een groot aantal particulieren, en de te vorderen bedragen klein zijn. wordt een effectieve interne controle mogelijk gemaakt door het aantal en de aard der vorderingen. Dit betekent eveneens, dat de negatieve methode kan worden toegepast. Het primaire doel van deze methode is immers als controle op het functioneren van de interne controle dienst te doen.

De accountant moet de verantwoordelijkheid aanvaarden voor de beslissing of de aard en de omvang van de antwoorden, tezamen met de overige door hem uitgevoerde controlewerkzaamheden, een voldoende grondslag vormen voor de beoordeling van de vraag of de debiteuren bonafide zijn. 11)

Evenals ten aanzien van de bijwoning van de voorraadopneming, stelde het committee vast, dat mededeling zou worden gedaan van het ontbreken van de bevestiging der uitstaande posten, zelfs, indien de accountant zich langs andere weg had overtuigd. 12)

\section{Controlewerkzaamheden in de loop van het jaar. ${ }^{13}$ )}

$E_{r}$ is in de laatste tijd een tendens waar te nemen um verschillende onderdelen van het onderzoek te verschuiven naar tijdstippen, liggend voor het einde van het jaar, teneinde de stroom van het werk te nivelleren. Daarmede hangt ten nauwste samen de doelmatigheid van het systeem van interne controle, daar deze een belangrijke invloed heeft op de mate, waarin dit verantwoord is. ${ }^{14}$ )

Onder behoorlijke omstandigheden kan de opneming van de voorraden in de loop van het jaar plaats vinden. Eveneens kunnen de bevestiging van uitstaande posten en het onderzoek naar de ouderdom daarvan, het onderzoek naar wijzigingen in de rekeningen van de vaste eigendommen, de kasmiddelen, tests van actieve rekeningen, en andere controle-maatregelen, naar veren worden geschoven.

11) Statements on Auditing Procedure No. 19, blz. 133.

12 Statements on Auditing Procedure No. 12, blz. 89.

13) Audit Work Prior to the Close of the Calendar Year.

14) Statements on Auditing Procedure No. 10, blz. 64. 
Deze tendens in de ontwikkeling van de controle betekent een bredere opvatting dan de gebruikelijke ,balance-sheet type of audit" en legt meer nadruk op het onderzoek van de interne controle, op het onderzoek van de actieve rekeningen en de bestudering van de zakelijke factoren, die ten grondslag liggen aan de cijfers.

\title{
Besluit
}

Het brede terrein, waarover deze 22 Statements (waarvan een aantal zich vooral bezig houdt met de problemen, verband houdende met de oorlogsperiode) zich uitstrekken, toont duidelijk in welke mate de vakgenoten zich voortdurend bezig houden met de controlenormen en de voortdurende pogingen om aldus de controle te verbeteren en te ontwikkelen.

\section{NIEUWS INZAKE WETGEVING, RESOLUTIES EN BESLISSINGEN OP HET GEBIED DER BELASTINGEN}

\author{
door Mr. Dr. E. Tekenbroek
}

\section{Toetsingrecht t.a.v. directiesalaris}

Met zijn arrest dd. 15 Mei 1946 (B. 8124) heeft de H.R. beslist, dat het de fiscus niet vrijstaat zonder meer de hoogte van het directiesalaris te toetsen aan de verrichte arbeid. Slechts als er uit omstandigheden opgemaakt moet worden, dat een uitbetaling, al wordt daaraan de schijn van een salarisuitkering gegeven, in werkelijkheid als een bevoordeling buiten het verband met de verrichte arbeid is bedoeld, kan een onttrekking (niet voor bedrijfsdoeleinden) worden aangenomen.

Een dergelijke omstandigheid kan o.i. zijn als aan een directeur-groot aandeelhouder een excessief salaris wordt uitbetaald; in schijn is er dan salaris, in werkelijkheid een winstuitdeling.

Men kan dit arrest beschouwen als een supplement op het arrest dd. 16 Januari 1946 (B 8023), waarop wij in het nummer van December 1946 onder de titel: "De strijd tegen verkapte winstuitdelingen niet ten einde" de aandacht vestigden.

\section{Subjectivering van bouwkosten}

Dd. 8 Mei 1946 (B 8119) heeft de H.R. een arrest gewezen, waarvoor in verband met de periode van opbouw, waarin het bedrijfsleven zich thans hier te lande bevindt, in deze rubriek de aandacht mag worden gevraagd.

Het geschil ging over de vraag of de rente van een geldlening, die de belastingplichtige voor de bouw van een nieuw bedrijfspand had opgenomen en de brandverzekeringspremie voor het tijdvak, waarin het bedrijfspand nog in aanbouw was, al of niet als bedrijfsonkosten aangemerkt kunnen worden. De belastingplichtige meende van wel, de inspecteur van niet. De R. v. B. I. te Rotterdam stelde de inspecteur in het gelijk. De belastingplichtige ging in cassatie en stelde o.m., dat het voor de berekening van de kostprijs van het pand geen verschil mag uitmaken of dit met eigen middelen dan wel met vreemde middelen gefinancierd wordt en al of niet tijdens de bouwtijd verzekerd is tegen brand; dergelijke subjectieve omstandigheden dienen, aldus de belastingplichtige in zijn beroepschrift in cassatie, buiten aanmerking te blijven.

De H.R., de door de R. v. B. gegeven motivering ten dele buiten aanmerking latende, bevestigde de uitspraak, daarbij o.m. overwegende, dat

$\mathrm{m} \mathrm{a} \mathrm{b}$ blz. 208 